\title{
Fragrance Impact on Driving Performance
}

\author{
Masria Mustafa1 ${ }^{1}$ Norazni Rustam², Rosfaiizah Siran ${ }^{3}$ \\ 1,2 Faculty of Civil Engineering, ${ }^{3}$ Faculty of Medicine, \\ Universiti Teknologi MARA, 40450 Shah Alam, Selangor, Malaysia \\ masria@salam.uitm.edu.my
}

\begin{abstract}
Previous studies have indicated that certain types of fragrance in the vehicle are useful in keeping the driver alert. This study was conducted to evaluate the effect of lavender or vanilla flavor fragrances toward driving performance. Ten human subjects were tested using the driving simulator in three different conditions; driving with vanilla, lavender flavor fragrance and driving without fragrance. A questionnaire was distributed to examine the emotion states of the driver after driving the simulator. Our results indicate that fragrance did not affect the speed reduction. The emotions of the drivers were calm due to the presence of the fragrance.
\end{abstract}

Keywords: driving performance, vehicle fragrance, speed reduction

eISSN: 2398-4279 @ 2017. The Authors. Published for AMER ABRA by e-International Publishing House, Ltd., UK. This is an open access article under the CC BY-NC-ND license (http://creativecommons.org/licenses/by-ncnd/4.0/). Peer-review under responsibility of AMER (Association of Malaysian Environment-Behaviour Researchers), ABRA (Association of Behavioural Researchers on Asians) and CE-Bs (Centre for EnvironmentBehaviour Studies), Faculty of Architecture, Planning \& Surveying, UniversitiTeknologi MARA, Malaysia.

https://doi.org/10.21834/ajqol.v2i5.8 


\subsection{Introduction}

Previous studies of (Bucchi et al., 2012) have suggested that psychological relationship exists between the driver and the infrastructure where emphasizing on this relationship will enhance a safe driving. Understanding driver behavior is very important to reduce accident rate (Machado et al., 2014). Driver condition such as fatigue is a contributing factor in many accidents (Gastaldi et al., 2014). Several explanations have been proposed in the literature regarding the performance of driving in regards to visual and auditory stimuli. On the other hand, many people do believe that senses of smell to the fragrance are responsible for the responses towards the environment via the connections in the brain. It has been demonstrated conclusively that the presence of fragrance affects the peoples' mood. One of the examples is a type of fragrance enhanced the alertness of the driver (Castro, 2008) while they are behind the wheel. Besides, recent study of (Mahachandra et al., 2015) proved that peppermint fragrance can help maintain drivers' alertness. Rather than adding yet another explanation for driving performance in conjunction with visual and auditory stimuli, in this study, we would like instead to focus on olfactory stimulation work

\subsection{Literature Review}

\subsection{Using fragrance and the impact on human behavior}

Our sensory system consists of several senses that include a sense of vision, sense of smell, sense of hearing, sense of touch and sense of taste. The sense of smell is a very sensitive than other sense, and it can immediately detect fragrances. Another research noted that human psychological functioning that includes perception and mood to cognitive processes and behaviors have the potential to be affected by a fragrance (Lenochova' et al., 2012). (Johnson, 2011) also stated that the human performance in all contexts come from the effect of fragrance.

Past research indicates that the presence of the fragrance can have positive and negative impacts on the athletic task performance to their psychology perceptions. The present of alerting fragrances in a vehicle can be used to maintain the alertness of sleepy drivers. Fragrances may give a better impression than listening loud sound (Castro, 2008). Many researchers believe that our sense of smell is the most directly connected to the part of our brain to process for a response. As a simple understanding, when we give a response with a sense of smell, our brain will give a response to the event or a situation before we think. Otherwise, different with other senses, we will think before coming out with any action. Therefore, it is realistic if a driver can use their response to smell and try to create an environment in the vehicle to get a positive influence such as the ability to control their behavior that can cause accidents. Another study on the effect of ambient fragrance on the reaction in humans has been explored. The finding showed that with the present of fragrance, the reaction time in a simple task is decreasing as compared with the no 
fragrance condition. Results also stated that environment with fragrance is the most importance influence on human behavior (Millot et al., 2002).

It has been widely known that fragrance is capable of altering the emotional state of humans. In the study of medicine (Lehrner et al., 2005), fragrance effect towards the mood of patients waiting for dental treatment was tested. The results showed that orange and lavender flavor seems to reduce the anxiety and significantly improved the mood of patients. Another study by (Ho \& Spence, 2005) investigated the effect of the peppermint fragrance on a dual task performance. Combined application of color and fragrance resulted in enhanced performance on a high demanding cognitive task incongruent conditions compared to incongruent conditions.

\subsection{Using driving simulator}

Noteworthy studies of (Silva et al., 2014) have utilized a real driving situation to test driver behavior and the interaction with road traffic environment. Recent research using a driving simulator has made great strides to the understanding of driver behavior. This has led some authors to suggest studies using a driving simulator. For example, (Rossi et al., 2011) used driving simulator to analyze driver fatigue. Furthermore, in the study of (Mahachandra et al., 2015) driving simulator was used to test peppermint fragrance to maintain vehicle driver's alertness. Their study demonstrated the use of an electroencephalograph (EEG) to monitor alertness level. The ongoing effort of using a driving simulator to test driving performance was also performed by (Gastaldi et al., 2014). An elegant conclusion was drawn where negative influence of the duration of driving tasks and circadian effects on driving performance increased the possibility of accidents.

A review of previous studies has helped to find out the idea of possible driver distractions and the variables that can be used to measure driving performance. Present understanding of the fragrance effect is limited as there has been very little attention in the literature emphasizing the relationship between using fragrance in the vehicle and driving performance. Some research explains the influence of fragrance effect using basic principles of perception. In this study, we would like to evaluate driving performance with the present of fragrance in the vehicle using a driving simulator.

\section{Methodology}

\subsection{The driving simulator}

For this study, a driving simulator as depicted in Figure 1(a) and (b) was used. Driving data were collected using an onboard computer via a custom-made signal data logger located in the cargo section of the car. We placed a video camera at the top right of the screen to identify whether the driver would give full focus during driving. Three different settings were 
used, setting with lavender fragrance, setting with vanilla fragrance and setting without any fragrance as control environment.

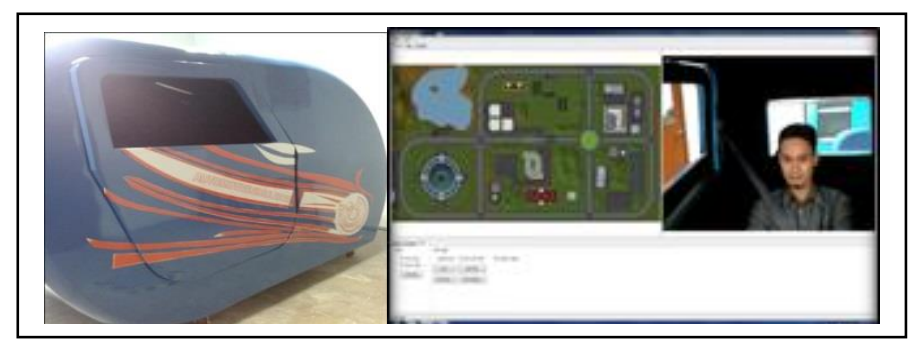

(a)

(b)

Figure1: (a) Driving simulator (b) The driving simulator setting

\subsection{The test subjects}

As our focus group is the young driver, ten healthy volunteers' drivers were recruited for this study with an age between 20-25 years old. Five (5) men and five (5) women were recruited to be the test subjects. All of them have had a valid driving license with less than eight years driving experience. Moreover, all drivers must be familiar to drive a manual-shift car.

\subsection{The driving task}

The subjects were asked to drive the simulator for 10 minutes to get familiar with the driving simulator. Performance measures, which can be classified as direct measurements and indirect measurement (Silva, 2014), are driver ability to perform the driving task at a level considered acceptable and safe. In this study, speed reduction was measured. Speed data was retrieved from the driving task for further exploration. These two simple tasks were given to the driver, scenario with lavender and vanilla fragrance and the control condition (scenario without fragrance). The drivers were asked to drive the circuit, consists of a corner, straight and roundabout.

\subsection{The questionnaire distribution}

A set of questions were distributed to the drivers after they finished the driving task. Relative Important Index (RII) (Equation 1) was used to interpret a set of data from the questionnaire. From the analysis, we determined the importance of the answers to be ranked. The level of answers from the questionnaire was converted to each factor as a relatively important index. The Relative Important Index is formulated as follow:

Where; $\quad \mathrm{RII}=\frac{\Sigma \mathrm{W}}{\mathrm{A} \times \mathrm{N}}$

$W=$ the weight given to each factor by the participants and rarige from 1 to 4

$\mathrm{A}=$ the highest weight (4); $\mathrm{N}=$ the total number of participants 


\subsection{Results and Discussions}

\subsection{Speed data analysis}

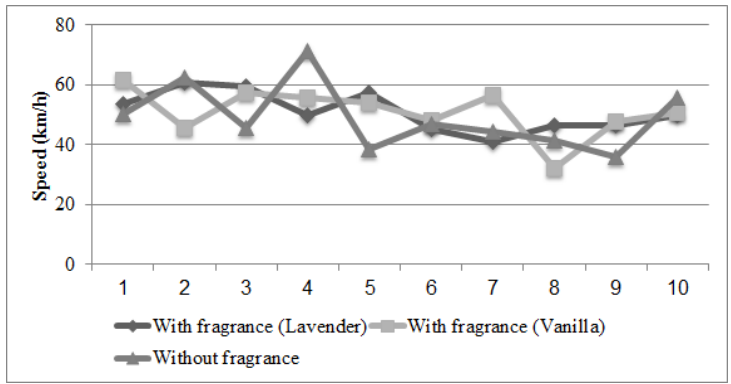

Figure 2: The average speed of individual test subjects at the Corner Road

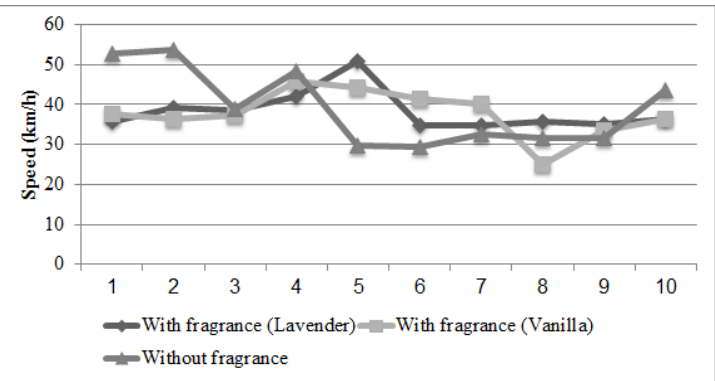

Figure 3: The average speed of individual test subjects at the Roundabout

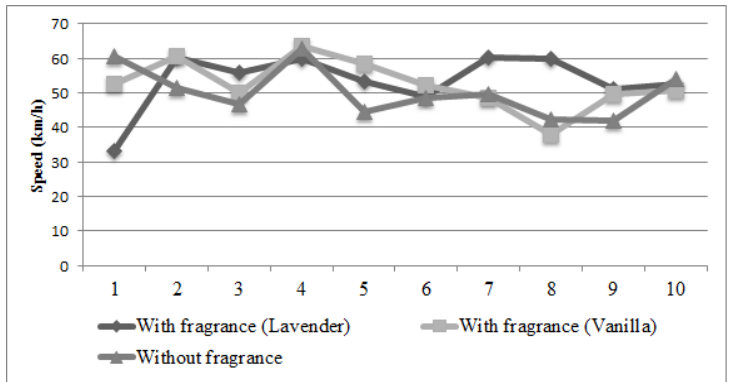

Figure.4: The average speed of individual test subjects at Straight Road

Figure 2, 3 and 4 depicted the results of the average speed of individual test subjects at three different locations; corner, straight, and roundabout area respectively. Looking at the 
visual presentation of the findings, there is a variability of speed once the fragrance is used the vehicle. The effect of fragrance on the average driving speed is shown in Figure 5. Analysis of simple main effects shows that at every location, average driving speed varies. Driving speed was reduced with the present of fragrance at the roundabout. The speed was higher at the straight road with the present of fragrance with the range of $52.4 \mathrm{~km} / \mathrm{h}$ (vanilla fragrance) and $53.4 \mathrm{~km} . \mathrm{h}$ (lavender fragrance) as compared to $50.2 \mathrm{~km} / \mathrm{h}$ for driving without any fragrance.

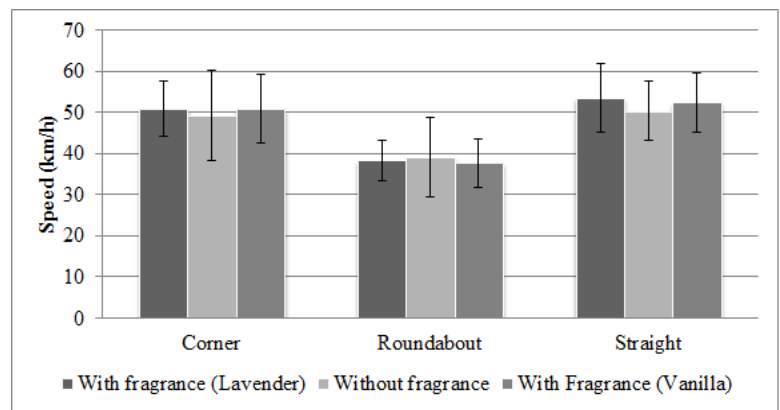

Figure 5: Average speed at different locations ( \pm S.D.)

\subsection{Ranking of emotions with lavender fragrance}

Table 1: Ranking of emotions with lavender fragrance

\begin{tabular}{|l|c|c|c|c|r|r|}
\hline & \multicolumn{7}{|c|}{ Frequencies of Scoring } & & \\
\hline Emotions & $\mathbf{1}$ & $\mathbf{2}$ & $\mathbf{3}$ & $\mathbf{4}$ & RII & Rank \\
\hline & & & & & & \\
\hline \hline Feel calm & $\mathbf{0}$ & $\mathbf{2}$ & $\mathbf{5}$ & $\mathbf{3}$ & $\mathbf{0 . 7 7 5}$ & $\mathbf{2}$ \\
\hline Be more alert & $\mathbf{1}$ & $\mathbf{1}$ & $\mathbf{5}$ & $\mathbf{3}$ & $\mathbf{0 . 7 5}$ & $\mathbf{4}$ \\
\hline Comfortable & $\mathbf{1}$ & $\mathbf{1}$ & $\mathbf{4}$ & $\mathbf{4}$ & $\mathbf{0 . 7 7 5}$ & $\mathbf{2}$ \\
\hline Relaxed & $\mathbf{1}$ & $\mathbf{1}$ & $\mathbf{3}$ & $\mathbf{5}$ & $\mathbf{0 . 8}$ & $\mathbf{1}$ \\
\hline More focus & 2 & 4 & 2 & 2 & 0.6 & 6 \\
\hline Feel fresh & $\mathbf{1}$ & $\mathbf{3}$ & $\mathbf{5}$ & $\mathbf{1}$ & $\mathbf{0 . 6 5}$ & $\mathbf{5}$ \\
\hline Vigor & 5 & 4 & 1 & 0 & 0.4 & 7 \\
\hline Depression & 9 & 1 & 0 & 0 & 0.275 & 8 \\
\hline Unable to concentrate & 10 & 0 & 0 & 0 & 0.25 & 12 \\
\hline Diff to focus & 9 & 1 & 0 & 0 & 0.275 & 8 \\
\hline Fatigue & 9 & 1 & 0 & 0 & 0.275 & 8 \\
\hline Anger & 10 & 0 & 0 & 0 & 0.25 & 12 \\
\hline Uncomfortable & 10 & 0 & 0 & 0 & 0.25 & 12 \\
\hline Anxiety & 9 & 1 & 0 & 0 & 0.275 & 8 \\
\hline 4=Severe, 3=Moderate, 2=Slight, 1=None & & & & \\
\hline
\end{tabular}


A set of data was analyzed from the questionnaire after the test subjects completed their driving task. Based on Table 1, there are five positive feeling that affected by lavender fragrance. Most of them feel relaxed which is rank (1) with $(R \|=0.8)$, followed by feeling comfortable, rank (2) with (RII=0.775), rank (3) feel calm (R\|l $=0.775)$, rank (4) be more alert with (RII=0.75) and feel fresh as the rank (5) with (RII=0.65). Thus, from the result of ranking analyzes, the major feeling is relaxed which means that the lavender fragrance showed a positive effect of the test subjects while driving.

\subsection{Ranking of emotions with vanilla fragrance}

Table 2: Ranking of emotions with vanilla fragrance

\begin{tabular}{|l|r|r|r|r|r|r|}
\hline & \multicolumn{7}{|c|}{ Frequencies of Scoring } & RII & Rank \\
\hline Emotions & $\mathbf{1}$ & $\mathbf{2}$ & $\mathbf{3}$ & $\mathbf{4}$ & $\mathbf{4}$ \\
\hline \hline Feel calm & $\mathbf{1}$ & $\mathbf{3}$ & $\mathbf{4}$ & $\mathbf{2}$ & $\mathbf{0 . 6 7 5}$ & $\mathbf{4}$ \\
\hline Be more alert & $\mathbf{0}$ & $\mathbf{3}$ & $\mathbf{5}$ & $\mathbf{2}$ & $\mathbf{0 . 7 2 5}$ & $\mathbf{1}$ \\
\hline Comfortable & $\mathbf{1}$ & $\mathbf{3}$ & $\mathbf{3}$ & $\mathbf{3}$ & $\mathbf{0 . 7}$ & $\mathbf{3}$ \\
\hline Relaxed & 2 & 5 & 2 & 1 & 0.55 & 6 \\
\hline More focus & $\mathbf{2}$ & $\mathbf{4}$ & $\mathbf{2}$ & $\mathbf{2}$ & $\mathbf{0 . 6}$ & $\mathbf{5}$ \\
\hline Feel fresh & 2 & 3 & 3 & 1 & 0.525 & 8 \\
\hline Vigor & 8 & 0 & 1 & 1 & 0.375 & 11 \\
\hline Depression & $\mathbf{1}$ & $\mathbf{3}$ & $\mathbf{2}$ & $\mathbf{4}$ & $\mathbf{0 . 7 2 5}$ & $\mathbf{1}$ \\
\hline Unable to concentrate & 4 & 1 & 4 & 1 & 0.55 & 6 \\
\hline Difficulty focusing & 6 & 0 & 2 & 2 & 0.5 & 10 \\
\hline Fatigue & 9 & 0 & 0 & 1 & 0.325 & 12 \\
\hline Anger & 10 & 0 & 0 & 0 & 0.25 & 14 \\
\hline Uncomfortable & 2 & 3 & 3 & 1 & 0.525 & 8 \\
\hline Anxiety & 8 & 2 & 0 & 0 & 0.3 & 13 \\
\hline 4=Severe, 3=Moderate, 2=Slight, 1=None & & & & & \\
\hline
\end{tabular}

Table 2 shows the analysis of ranking of emotion with vanilla fragrance. The results are contradicted with lavender fragrance concerning their highest rank (1). Depression was rank to be (1) with $(R \|=0.725)$, rank (2) is more alert ( $R \|=0.725)$, followed by feeling comfortable with $(R \|=0.7)$, feel calm rank (4) with ( $R \|=0.675)$ and the last rank is more focus $(R \|=0.6)$.

\subsection{Ranking of emotions without fragrance}

Table 3 represents the analysis of emotions for the condition without fragrance. The results showed that there is a positive and negative effect on rank (1) to rank (5). The highest rank indicates a negative effect which is uncomfortable with $(R \|=0.575)$, followed by the second rank (2) which is represented as a positive emotion; be more alert with (RII=0.50). Rank (3) is a negative emotion that is unable to concentrates (RIl=0.45). Lastly, rank (4) and (5) are presented by positive effects. In general, the test subjects give a positive emotions respond which is similar with the presence of fragrance. 
Table 3: Ranking of the emotions without fragrance

\begin{tabular}{|l|c|c|c|c|r|r|}
\hline & \multicolumn{7}{|c|}{ Frequencies of Scoring } & RII & Rank \\
\hline Emotions & $\mathbf{1}$ & $\mathbf{2}$ & $\mathbf{3}$ & $\mathbf{4}$ & $\mathbf{1}$ & $\mathbf{2}$ \\
\hline \hline Feel calm & $\mathbf{6}$ & $\mathbf{2}$ & $\mathbf{1}$ & $\mathbf{1}$ & $\mathbf{0 . 4 2 5}$ & $\mathbf{4}$ \\
\hline Be more alert & $\mathbf{4}$ & $\mathbf{3}$ & $\mathbf{2}$ & $\mathbf{1}$ & $\mathbf{0 . 5 0}$ & $\mathbf{2}$ \\
\hline Comfortable & 8 & 1 & 1 & 0 & 0.325 & 8 \\
\hline Relaxed & $\mathbf{4}$ & $\mathbf{5}$ & $\mathbf{1}$ & $\mathbf{0}$ & $\mathbf{0 . 4 2 5}$ & $\mathbf{4}$ \\
\hline More focus & 10 & 0 & 0 & 0 & 0.25 & 12 \\
\hline Feel fresh & 9 & 1 & 0 & 0 & 0.275 & 11 \\
\hline Vigor & 8 & 1 & 0 & 0 & 0.25 & 12 \\
\hline Depression & 8 & 1 & 1 & 0 & 0.325 & 8 \\
\hline Unable to concentrate & $\mathbf{5}$ & $\mathbf{3}$ & $\mathbf{1}$ & $\mathbf{1}$ & $\mathbf{0 . 4 5}$ & $\mathbf{3}$ \\
\hline Diff to focus & 6 & 2 & 2 & 0 & 0.4 & 6 \\
\hline Fatigue & $\mathbf{7}$ & 2 & 1 & 0 & 0.35 & 7 \\
\hline Anger & 10 & 0 & 0 & 0 & 0.25 & 12 \\
\hline Uncomfortable & $\mathbf{4}$ & $\mathbf{3}$ & $\mathbf{3}$ & $\mathbf{1}$ & $\mathbf{0 . 5 7 5}$ & $\mathbf{1}$ \\
\hline Anxiety & 8 & 2 & 0 & 0 & 0.3 & 10 \\
\hline
\end{tabular}

4=Severe, 3=Moderate, 2=Slight, 1=None

The use of fragrance may result in enhanced performance on a high demanding cognitive task incongruent conditions compared to incongruent conditions. There are not so many studies focusing on the effects of fragrance towards driving performance. Comparing fragrance analysis approach while driving, (Fruhata et al., 2013) make important observations in using fragrance of a grapefruit as aromatherapy for sleepy drivers. Their interesting findings show that stimulating senses such as smelling was found to expand the arousal effect. The findings show an obvious resemblance to our findings where using lavender fragrance in the car improve the driver's feelings towards calming, alertness, comfortable, relaxed and feel fresh. Besides, the findings are also consistent with (Raudenbush et al., 2009) where the present of peppermint and cinnamon fragrance increase the alertness of the driver. Vanilla fragrance was successful in increasing ratings of feel calm, alertness, comfort, more focus but high depression. This contradiction has also been pointed out by (Moss et al., 2003) whereby the lavender fragrance decreases the working memory performance and attention based task. In our study, the driving speed reduction does not affect much with the present of fragrance. The results might be due to the level of adaptation to the driving simulator. However, this assumption is rather arbitrary where (Sahami and Sayed, 2013) concluded that adaptation times for test subjects are not statistically different when using a driving simulator. The amounts of skill transfer are the same.

\subsection{Conclusion}

In conclusion, we found no evidence that the presence of fragrance affects to the speed 
reduction. For the condition without fragrance, it shows the similar results with both conditions (lavender and vanilla fragrance). From this finding, we achieved the first objective of this study that aims to investigate the effect of fragrance in terms of speed reduction. In examining the feelings of the driver under different conditions, (without fragrance and with the fragrance), the analysis indicates that fragrance may affect the emotion of the drivers whether a positive effect or negative effect. The finding shows the emotions of the drivers is under control due to the presence of fragrance (lavender and vanilla) that led them to the positive feelings which feel relaxed, more comfortable, be more alert and feel fresh. There are some positive feelings that affect to drivers in condition without fragrance. These positive feelings exist because of some people may be very sensitive to the smell of the fragrance. Thus, they feel comfortable to drive without fragrance. The paper addresses an important parameter, and that is human behavior. The current results add to the growing literature on the effects of using fragrance in the vehicle, though more research on the effects of varying the driving conditions is needed. The findings will help in decision-making regarding the use of air fresheners in the vehicles.

\section{Acknowledgement}

This study is funded by Universiti Teknologi MARA (UiTM)

\section{References}

Bucchi, A., Sangiorgi, C., \& Vignali, V. (2012). Traffic Psychology and Driver Behavior. Procedia - Social and Behavioral Sciences, 53(0), 972-979.

Castro, C. (2008). Human Factors of Visual and Cognitive Performance in Driving: CRC Press

Gastaldi, M., Rossi, R., \& Gecchele, G. (2014). Effects of Driver Task-related Fatigue on Driving Performance. Procedia - Social and Behavioral Sciences, 111(0), 955-964.

Ho, C., \& Spence, C. (2005). Olfactory facilitation of dual-task performance. Neuroscience Letters, 389(1), 35-40.

Johnson, A. J. (2011). Cognitive Facilitation Following Intentional Odor Exposure. Sensors, 11(5), 5469-5488.

Lehrner, J., Marwinski, G., Lehr, S., Johren, P., \& Deecke, L. (2005). Ambient odors of orange and lavender reduce anxiety and improve mood in a dental office. Physiology \& Behavior, 86(1-2), 92-95.

Lenochova', P. n., Vohnoutova', P., Roberts, S. C., Oberzaucher, E., Grammer, K., \& Havli'cek, J. (2012). Psychology of Fragrance Use: Perception of Individual Odor and Perfume Blends Reveals a Mechanism for Idiosyncratic Effects on Fragrance Choice. PLoS One, 7(3).

Machado, J. L., de Oña, J., de Oña, R., Eboli, L., \& Mazzulla, G. (2014). A Stated Preference Experiment for Understanding Drivers' Risk Perception. Procedia - Social and Behavioral Sciences, 162(0), 263-272. 
Mahachandra, M., Yassierli, \& Garnaby, E. D. (2015). The Effectiveness of In-vehicle Peppermint Fragrance to Maintain Car Driver's Alertness. Procedia Manufacturing, 4, 471-477.

Millot, J.-L., Brand, G., \& Morand, N. (2002). Effects of ambient odors on reaction time in humans. Neuroscience Letters, 322(2), 79-82.

Moss, M., Cook, J., Wesnes, K., \& Duckett, P. (2003). Aromas of rosemary and lavender essential oils differentially affect cognition and mood in healthy adults. Int $J$ Neurosci, 113(1), 15-38.

Rossi, R., Gastaldi, M., \& Gecchele, G. (2011). Analysis of driver task-related fatigue using driving simulator experiments. Procedia - Social and Behavioral Sciences, 20(0), 666-675.

Silva, F. P. d. (2014). Mental Workload, Task Demand and Driving Performance: What Relation? Procedia - Social and Behavioral Sciences, 162(0), 310-319.

Silva, F. P. d., Santos, J. A., \& Meireles, A. (2014). Road Accident: Driver Behaviour, Learning and Driving Task. Procedia - Social and Behavioral Sciences, 162(0), 300-309. 